Article

\title{
Exploring challenges to implementation of IT service management system ISO 20000: Implications in managing big data in emerging economy
}

\author{
Nafis Ahmad, Md. Golam Rabbany and Syed Mithun Ali * \\ Department of Industrial and Production Engineering, Bangladesh University of Engineering and \\ Technology, Dhaka-1000, Bangladesh; ahmadn.ipe.buet@gmail.com (N.A.); rabbany_kuet@hotmail.com \\ (G.R.) \\ Correspondence: syed.mithun@gmail.com; Mobile no. +8801916034096; Fax : +88028613046
}

\begin{abstract}
This study contributes to the literature by exploring challenges to implementing ISO 20000-1 in an emerging economy context, and suggests ways to overcome these challenges. A survey-based methodology was adopted. The data were analyzed using principal component analysis. The results indicated that senior management support was the most significant challenge for the successful implementation of IT Service Management (ITSM) systems. Other significant challenges were the justification of significant investment, premium customer support, cooperation and co-ordination among IT support teams, proper documentation, and effective process design The findings help managers introduce IT service management system (ISO 20000-1:2011) as well as improving IT service delivery system in IT support organizations for managing big data in an emerging economy. In the future, cross-firm and cross-country studies on challenges to ISO 20000 can be conducted. Also, interpretive structural model (ISM) can be formulated to examine the interrelationships among the identified challenges to ISO 20000.
\end{abstract}

Keywords: Business excellence; information technology; implementation challenge; ISO 20000; big data management.

\section{Introduction}

Information and communication technology (ICT) is the unified communications through the combination of telecommunications, computers and other enterprise software, storage, and audio-visual systems. ICT help users and stakeholders to access, store, transfer, retrieve, and handle necessary information [13], and has a significant effect on increasing the productivity of firms and boosting the national economy of a country [4]. ICT helps in handling a large volume of data. The volume of data is exploding - in part because they are increasingly gathered by cheap and numerous information- sensing Internet of things (IoT) devices such as mobile devices, aerial (remote sensing), software logs, cameras, microphones, radiofrequency identification (RFID) readers and wireless sensor networks. In 2020, the global information capacity can be estimated as four zettabytes (four billion 
terabytes), with this number doubling every 3 years [5]. In a recent study, Haseeb et. al. [6] shows that elements of Industry 4.0 such as big data, IoTs and smart factory will promote information technology (IT) implementation for sustainable business performance. The money spent on IT worldwide has been most recently estimated as the US $\$ 3.5$ trillion and is currently growing at 5\% per year, doubling every 15 years [7].

A few recent studies on ISO 20000 management system appear in the literature. Cots et al. [8], based on some ISO 20000 certified organizations in Spain, mentioned several benefits of ISO 20000 IT service management certification. Leite et al. [9] registered ISO 20000 certification process and presented a framework to implement ISO 20000. Disterer [10] documented the objectives and instruments of ISO 20000 for IT. The instruments contain customer focus, standardization, process orientation, certification of organization and people, continuous improvement initiatives, and in line to best practices.

Apart from ISO 20000, some researchers explored challenges to implement other international standard certification processes, for example, challenges to implement environment management system ISO 14001 in emerging countries [11], challenges to establish quality and safety standard in the food industry [12], among others. However, exploring challenges for implementing ISO 20000 is a rarely studied topic in the academic literature. This study is grounded on filling in this research void by taking a real-life example of an IT firm operating in an emerging economy.

Bangladesha developing country-has placed the ICT sector on the top of its development agenda to achieve the status of being a middle-income country by 2021 [13] . The ICT sector can be a great means to create employment in this country without creating much pressure on its environment and energy resources. In 2015, the Government of Bangladesh has enacted an appropriate guideline for the ICT and declared it as an important sector. It is projected that within five years the ICT sector will contribute $1 \%$ to the Bangladesh's total GDP (Gross Domestic Product) and 
generate employment for 150,000 ICT professionals [14]. The ICT can reduce unemployment to a great extent and have a multiplier effect on a country's economy. For instance, The ICT industry of Bangladesh has advanced to a significant extent over the past decade and generated around \$300 million revenue yearly [15]. Bangladesh has an enormous potential in this sector, but it is a long way to reap the harvest of global ICT revolution. Therefore, the need to invest in ICT infrastructure and build up skilled ICT human resources is crucial.

The influence of big data analytics on information systems, IT enabled services, and information technology is huge and requires lots of attention [16] . Thus, several authors have emphasized the importance of information/information technology for managing big data for enterprises. Kang et al. [17] proposed a framework for deriving real-time information from big sensor data through edge computing technique. Kaufmann [5] Presented a model for big data management is for operationalizing value creation from big data by associating business goals with information technology (IT) aspects. Fung [18] examined how big data management can improve the IT service delivery of an IT organization. Zhang et al. [19] discussed how big data impacts the IT industry now-a-days. They presented some challenges, opportunities and bottlenecks faced by the IT industry in a big data environment.

This study fills the identified research gap by addressing the following research questions.

(i) What are the challenges that IT firms face to the implementation of ISO 20000 in an emerging economy?

(ii) What are the theoretical and practical implications of the challenges to ISO 20000 for an emerging economy?

To achieve the above research questions, this research fulfills the following research objectives. 
(a) Identifying the challenges to IT service management standard ISO 20000 from a review of extant literature and managers' feedback.

(b) Investigating the challenges to ISO 20000 using statistical analysis.

(c) Proposing a framework for implementing ISO 20000 in IT management firms.

(d) Suggesting some implications of identified challenges to ISO 20000 for local and multinational IT firms.

To gain the mentioned objectives, an empirical study was conducted. The required data for the study, based on a 1-7 Likert scale, were collected through surveys, interviews, telephonic conversations, and meetings with IT firm managers and staff. The reliability or internal validity of the questionnaires was tested using Cronbach's $\alpha$ [20]. A Student t-test [21] was performed to check whether the perception by process managers and service owners as well as other different groups was similar or not. The ranking of challenges were obtained basing on the mean and standard deviation calculated from the survey responses. Following the survey responses, a reference model to implement ISO 20000 is proposed in this study.

The remainder of this paper is organized as follows: Section 2 reviews the literature. Section 3 presents an overview of the case company. Research methodology is illustrated in Section 4. A framework for implementing ISO 20000 is given in Section 5. Section 6 offers discussions on findings. Section 7 concludes this paper.

\section{Literature review}

ISO 20000 is a service management system standard. It defines and characterizes the requirements for the service provider to plan, organize, implement, operate, monitor, review, and improve a short message service (SMS) [22]. The requirements for implementing ISO 20000 include the functions such as design, transition, delivery, and improvement of services to fulfill agreed service 
requirements. This standard are utilized by an organization searching for or taking services from other organizations of service providers. A service provider can employ it for monitoring, measuring and reviewing its service management processes through the implementation and operation of ISO 20000-1:2011.

\subsection{ISO 20000 certifications worldwide}

As of December 2015, 2778 organizations have received ISO 20000 certifications to manage their IT services. Figure 1 illustrates the information of IT service management system (ITSMS) certifications of different regions around the world. Europe has the 1120 organizations which are $40.3 \%$ of the total number of organization with ISO 20000 certifications globally. Africa has the least number of certifications with only $1 \%$ of the total. East Asia and Pacific region received 758 certifications which are $27.3 \%$, Central and South Asia received 434 certifications (15.6\%), North America received 254 certifications (9.1\%), Middle East received 99 certifications (3.6\%), and Central and South America received 88 certifications (3.2\%) respectively. India has 425 organizations that received ISO 20000 certification, and it is the highest number of ISO 20000 certifications in the world for a single country. Figure 2 displays the top ten countries that obtained the most ISO 20000 certifications. The remaining top ten countries that have received ISO 20000 certifications are Japan (299), Spain (231), USA (223), UK(197), China (138), Germany (108), Thailand (97), Czech Republic (90) and Italy (86). 


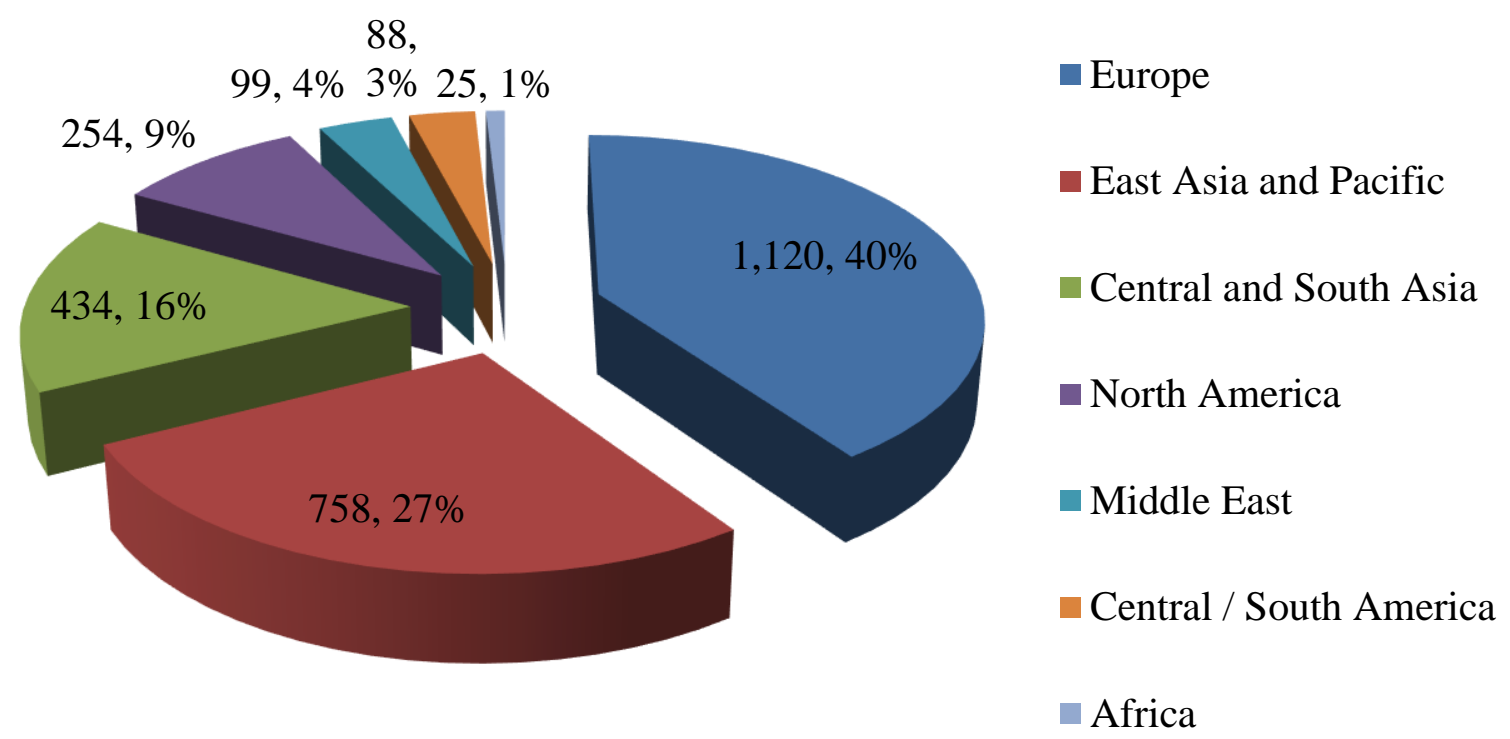

Figure 1 Region wise ISO 20000 certifications [23]

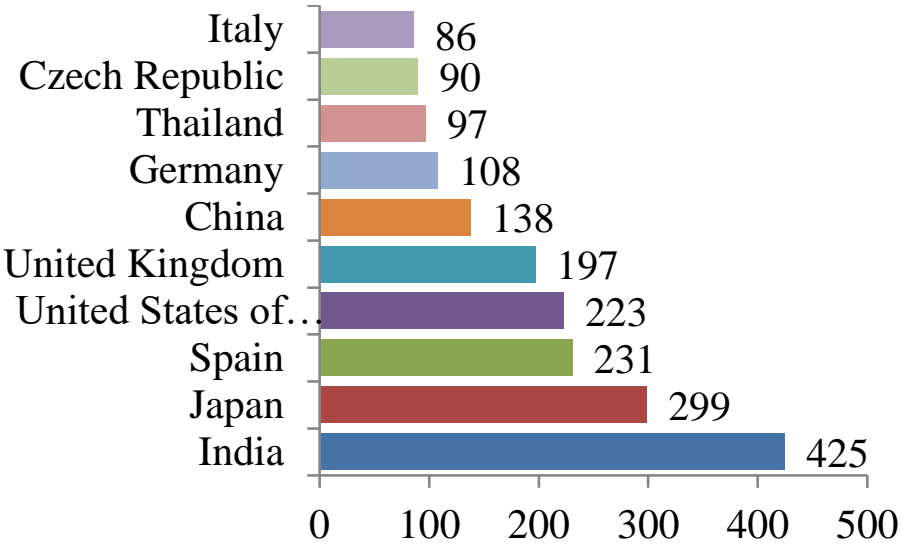

Figure 2 Top ten countries in the world for ISO 20000 Certifications [23]

IT-based organizations received a total of 735 ISO 20000 certifications. Figure 3 shows the top five industries that received the highest number of ISO 20000 certifications. The remaining top five industries are food products, beverages and tobacco (74), electrical and optical equipment (55), other Services (29) and financial intermediation, real estate, rental (17), respectively. 


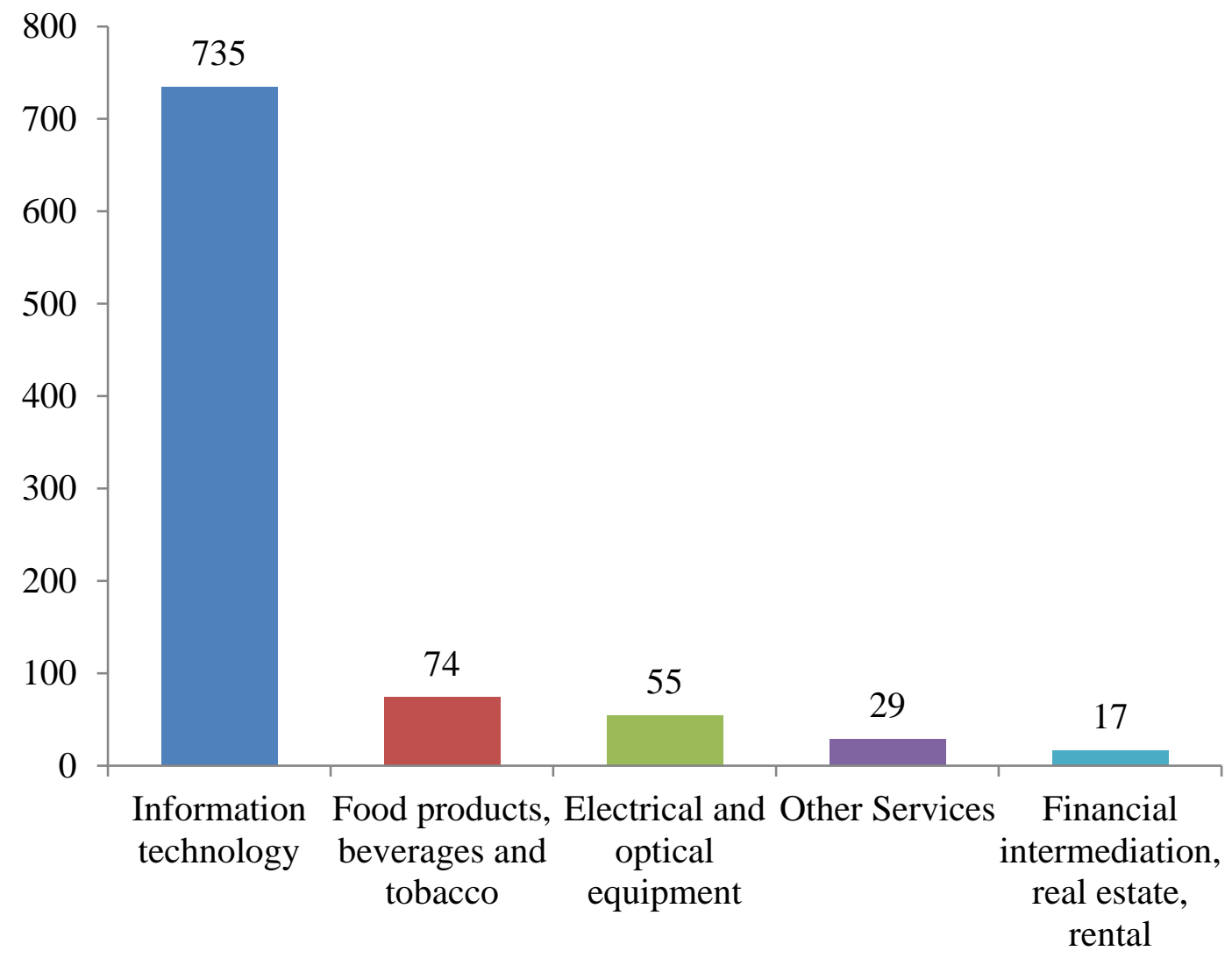

Figure 3 Major industrial sectors for ISO 20000 Certifications [23]

\subsection{Challenging areas for implementation of ISO 20000}

Implementation of ISO 20000 requires investigating organizational requirements, policies and priorities. Jäntti [24] presented a case study on implementing IT service management systems based on three different organizations in Finland, namely Tieto Finland, the Finnish Tax Authority and Istekki. In Tieto Finland, lack of service level agreements, information sharing on incident resolutions, an increased number of open incidents, and a lack of transparency on support activities were the major challenges for implementing IT service management system. The lack of appropriate database management system, the interface between incident management and problem management, identification of repeating incidents from the service desk system were the challenges for implementing ISO 20000 in the Finnish Tax Authority, whereas lack 
of reporting and visibility of changes made, and a lack of skilled manpower are the challenges found in Istekki during implementing ISO 20000.

To overcome the challenges identified in his study, Jäntti [24] recommended a number of solutions including priority coding system, implementation of service level agreement interface between incident management and problem management, identification of repeating incidents, implementing change management reports and introducing IT service management tools.

According to Cater-Steel et al. [25], relationships with vendors, senior management support, project champion, changes in corporate culture are some challenges for implementing ISO 20000 in ITSM organizations. Senior management must appropriately resource to implement ISO 20000 in any organization. Developing close relationships with vendors, effective change management process, and placing a benefits realization plan to track and communicate tangible and intangible benefits were some suggestions to overcome the challenges of implementing ISO 20000 in ITSM organizations [25].

Resistance to accepting new processes and a lack of knowledge for managing such changes are the main challenges to implementing ISO 20000 or IT service management standard in any ITSM organizations [26]. Another study [27] found that the main challenge of ITSMS implementation is that chief information officers have to face IT budgets deficiency of their organizations. Iden and Eikebrokk [28] ( reviewed the extant literature related to the implementation issues of IT Service Management (ITSM) and the Information Technology Infrastructure Library (ITIL). They found that key success factors, motives, implementation and readiness status, and benefits are some popular research areas on ITSM and ITIL.

\section{Overview of the case company}

This research was conducted in ACIS Ltd., a leading organization providing management consulting, technology and outsourcing services with more than 
293,000 employees. It operates in more than 200 cities in 56 countries. It has been recognized as the number one global outsourcing company and is ranked as the number 10 on FORTUNE's Blue Ribbon Companies list in 2015.

In Bangladesh, it has 430 employees including regular and temporary staffs working in four divisions namely: technology division, commercial division, finance division, and human resources division. The technology division is the largest one consisting of 289 staffs (67\%). They are grouped into IT infrastructure management $(155,36 \%)$, customer application and systems (76, 18\%), project management (20, $5 \%)$, telecom product and billing $(28,7 \%)$ and revenue assurance and ERP $(10,3 \%)$. The commercial division has 108 staffs (25\%) working in three groups which are marketing and brand communication $(15,3 \%)$, sales $(25,6 \%)$ and customer services $(68,16 \%)$. The finance division consists of 20 staffs (5\%) with two departments which are payments and asset management $(9,2 \%)$ and accounts management $(11,3 \%)$. Human resources division consists of 13 staffs (3\%) with two departments which are payroll $(6,2 \%)$ and employee affairs $(7,2 \%)$.

\section{Research Methodology}

In this research, information was collected from the literature and a case study-based empirical investigations. The empirical investigation was conducted in in ACIS Ltd., which is one of the world's leading organizations in the domain of management consulting, technology and outsourcing services. The details of the company is found in Section 3. An empirical study is an investigation based on data, which were collected through surveys, interviews, telephonic conversations, and meetings. During the interview process, participants' responses were recorded verbatim to ensure the optimum accuracy in reflecting the participants' understanding of the topic [29]. All answers were summarized in each category and duplicate items were removed. Thus, a list of challenges were identified. For each challenge identified, the interviewer kept a record of how many participants had mentioned it during the interviews. Based on the interviews/meeting and literature 
study, several challenges were identified. Then survey questions were prepared and presented to 99 employees of ACIS who were working in different departments and involved in the implementation of ISO 20000.

During the survey, participants were asked to put their opinion according to their importance. Important questions were asked first and a 7-point Likert scale was employed to collect the opinion where 1 = Strongly Disagree, 2 = Quite Disagree, $3=$ Slightly Disagree, 4 = Neutral, 5 = Slightly Agree, $6=$ Quite Agree and $7=$ Strongly Agree. Demographic questions were asked to identify the participant uniquely. This step allowed us to rank the challenges. Challenges with higher mean or lower standard deviation were given a higher ranking. If more than one challenge got the same average rating, the item with smaller standard deviation was ranked higher. Factor analysis [30] was performed to find out the relationship among different challenges and to categorize them. Here, rotated component matrix is used to perform factor analysis. Cronbach's $\alpha$ was quantified to test the reliability of questionnaires, and an independent $\mathrm{t}$-Test was performed to test whether a group of people is thinking differently or not. After factor analysis, relevant challenges were grouped together. Thus, we finalized all challenges to implement ISO 20000.

\subsection{Participant selection for the case study}

During data collection, 430 employees were working in ACIS Ltd. From 430 employees, 99(23.2\%) employees, directly involved in implementation of ISO 20000, were selected for the survey.. 2 out of the 99 employees were missed out as they were out of the country or left the organization. 45 out of 99 staffs were interviewed including service owners (25), process managers (11), high officials (4), ISO core team members (3) and consultant (1) to get the specific challenges in different sections. All staff (99) were included in the survey. Out of 99 participants, 92 participants completed the survey and sent back their opinion i.e., response rate was $92.93 \%$. Three responses were excluded due to some discrepancies or mistakes in filling up the questionnaire. 


\subsection{Views of IT professionals in ACIS}

Before the survey, interviews and meetings with IT professionals of ACIS Ltd. were arranged to know their views on the implementation of ISO 20000 in ACIS. During the interviews and meetings, the following questions were asked to settle the platform of this research.

- What is your experience working with ISO 20000 implementations in ACIS Ltd.?

- What is your point of view towards ISO 20000 implementation in ACIS Ltd.?

Throughout the interviews and meetings, the researchers found that the views towards ISO 20000 as an ITSM framework were positive. Most of the participants thought employees were more united than before and it happened due to the implementation of ISO 20000. Many participants also believed that ISO 20000 aligns with IT services to international IT market and it standardizes the services. Figure 4 shows the summaries of views of IT professionals of ACIS. $66 \%$ of the interviewees expressed that ISO 20000 had been implemented to standardize IT Services and align with the international IT market.

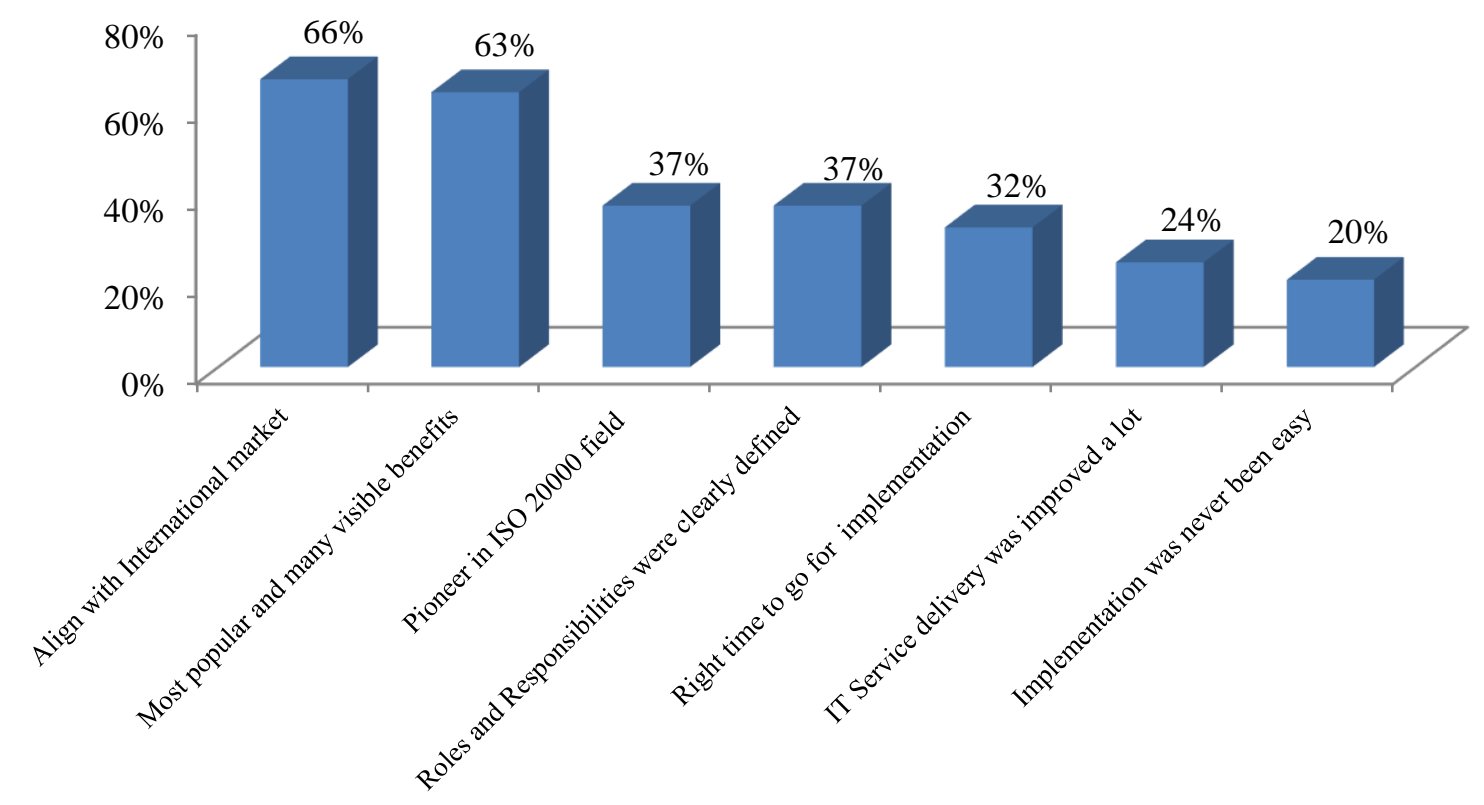

Figure 4 Summaries of Views of IT Professionals of ACIS. 
As observed, 63\% participants believed that ISO 20000 was the most popular IT service standard in the world and many visible benefits could be achieved. $37 \%$ participants said that ISO 20000 was really beneficial for ACIS and ACIS became the pioneer in this field. 37\% participants believed that roles and responsibilities were clearly defined and it was the key factor of implementation. 32\% participants said that ACIS were in perfect position to go for implementation of ISO 20000. 24\% participant opined that IT service delivery was improved a lot after implementation of ISO 20000. 24\% participants believed that ISO 20000 was different from other standard and difficult to implement.

\subsection{Survey data analysis}

As mentioned earlier, out of 430 employees, 99 were selected which is $23.02 \%$ of the total employees. We deliberately selected the employees who handled IT related issues or involved in the process of implementing ISO 20000 in the company. The employees were not selected randomly rather purposively, known as purposive sampling [31]). Among the selected employees, more than $98 \%$ participants were directly engaged in putting ISO 20000 in practice. During interviews, each of the participants was asked the following questions to get their insights on the challenges associated with the implementation of ISO 20000 in ACIS Ltd.

- What are the challenges you identify for ACIS Ltd. to implement ISO 20000?

Several challenges were identified after analyzing interviewee's responses that reflected the participants' understanding of the challenges. According to process managers, understanding processes and its benefits by the IT support team (11 out of $11,100 \%)$, justification on short term and long term benefits (9 out of 11,82\%) and investing a large amount of money in ITSM tools (8 out of $11,73 \%$ ) were the challenging areas during implementation of ISO 20000 in ACIS Ltd. Appropriate process managers selection (25 out 25, 100\%), restructuring organization and forming central ISO monitoring team (23 out 25, 92\%), implementing all processes in service (22 out of $25,88 \%$ ), adaptation, customization and governance (20 out of 
$25,80 \%$ ), continuing premium customer support (19 out $25,76 \%$ ) and readiness and alignment with changes $(17$ out 25,68$)$ were the challenging areas mentioned by service owners. ISO core team members mentioned maturity of all standards (3 out of 3,100$)$ and process understanding by senior managers ( 2 out $3,67 \%$ ) were the challenging areas during implementation. Commitment and budget (4 out 4, 100), understanding benefit by lead customer (4 out 4, 100\%), justification on cost-benefit analysis (4 out 4,100\%), technical knowledge of IT support people (2 out $4,50 \%$ ) and relationship among standards (2 out of 4,50\%) were the challenging areas mentioned by high officials. During interviews, all interviewees mentioned that collaboration and balanced workload distribution (32 out of $41,84.5 \%$ ), cooperative attitude from premium customers (27 out of $41,65.85 \%$ ), continuing premium customer support (24 out of 41,58.53\%) and maintaining quality documentation (16 out of $41,39.01 \%$ ) were the challenging areas during implementation project.

Based on the interviews/meetings and literature study, several challenging areas were identified. Then survey questionnaires were prepared covering all of them and sent to 99 employees of Accenture Communications Infrastructure Solutions Ltd (ACIS). In this case, structured questions (closed-ended questions) were given the priority over open-ended questions. A 7 point Likert scale was used to collect the opinion where 1 = Strongly Disagree, 2 = Quite Disagree, 3 = Slightly Disagree, 4 = Neutral, 5 = Slightly Agree, $6=$ Quite Agree, and $7=$ Strongly Agree. Demographic questions were asked to identify the unique participant. Several challenging areas were identified and uniquely defined by code name after analyzing responses. After that, a ranking of the identified challenges was done based on mean, standard deviation and variance.

Table 1 illustrates the initial ranking of the challenges based on mean, standard deviation and variance. Here, the highest mean or lower standard deviation is given the highest rank and so on. Each challenging area is assigned by a code such as understanding processes and its benefits by IT support teams (C-1), justification on short term and long term benefits (C-2), investing large amount of 
money in ITSM tools (C-3), appropriate process managers selection (C-4), restructuring organization and forming central ISO monitoring team (C-5), implementing all processes in service (C-6), commitment and governance (C-7), continuing premium customer support (C-8), readiness and alignment with changes (C-9), designing and customization (C-10), believe in benefit and processes understanding by high officials (C-11), budget and financial planning (C-12), understanding benefit by lead customer (C-13), justification on cost-benefit analysis (C-14), technical knowledge of IT support people (C-15), relationship among standards (C-16), collaboration and well distribution of workload (C-17), cooperative attitude from premium customers (C-18), continuing premium customer support (C-19), and maintaining quality documentation (C-20).

Cronbach's $\alpha$ was used to quantify the reliability of the questionnaires. Cronbach's $\alpha$ value 0.814 indicates a good reliability. It was also observed that Cronbach's $\alpha$ score decreased if some items were removed. Thus, it can be concluded that those questions were reliable enough to find out the desired value. Student t-test was done to check whether the perception by process managers and service owners as well as other different groups was similar or not. It can be seen that there was no significance difference among participants perception. Table 2 presents the results of factor analysis using a principal component analysis (PCA) and the Varimax with Kaiser Normalization rotation method until the eigenvalue of the each factor was greater than 1. As observed, the rotation was converged in 5 iterations. PCA are statistical techniques used to find out variables that are correlated with one another but largely independent of other subsets of variables [32].

Table 1 - Initial ranking of the challenges based on mean, standard deviation and variance 


\begin{tabular}{|c|c|c|c|c|c|c|c|}
\hline $\begin{array}{c}\text { Initial } \\
\text { Ranking }\end{array}$ & Code & $\begin{array}{c}\text { Response } \\
\text { (Valid) }\end{array}$ & $\begin{array}{l}\text { Response } \\
\text { (Invalid) }\end{array}$ & Mean & $\begin{array}{l}\text { Standard } \\
\text { deviation }\end{array}$ & Variance & Sum \\
\hline 1 & C-12 & 91 & 6 & 6.64 & 0.48 & 0.23 & 595 \\
\hline 2 & $C-7$ & 90 & 7 & 6.54 & 0.50 & 0.25 & 498 \\
\hline 3 & C-11 & 89 & 8 & 6.41 & 0.62 & 0.38 & 395 \\
\hline 4 & $C-5$ & 90 & 7 & 6.30 & 0.68 & 0.46 & 577 \\
\hline 5 & C-4 & 90 & 7 & 6.02 & 0.75 & 0.56 & 522 \\
\hline 6 & C-15 & 89 & 8 & 5.89 & 0.76 & 0.57 & 505 \\
\hline 7 & C-17 & 90 & 7 & 5.80 & 0.88 & 0.77 & 372 \\
\hline 8 & C-1 & 89 & 8 & 5.76 & 0.78 & 0.61 & 349 \\
\hline 9 & C-9 & 89 & 8 & 5.67 & 0.75 & 0.56 & 513 \\
\hline 10 & C-6 & 89 & 8 & 5.53 & 0.77 & 0.59 & 333 \\
\hline 11 & C-18 & 90 & 7 & 5.43 & 0.69 & 0.47 & 542 \\
\hline 12 & C-2 & 90 & 7 & 5.37 & 0.70 & 0.49 & 530 \\
\hline 13 & C-8 & 90 & 7 & 5.28 & 0.66 & 0.43 & 489 \\
\hline 14 & C-16 & 89 & 8 & 4.85 & 0.85 & 0.72 & 478 \\
\hline 15 & C-10 & 89 & 8 & 4.58 & 1.04 & 1.09 & 470 \\
\hline 16 & $C-13$ & 89 & 8 & 4.44 & 0.93 & 0.86 & 432 \\
\hline 17 & C-20 & 89 & 8 & 4.33 & 0.95 & 0.90 & 591 \\
\hline 18 & C-3 & 89 & 8 & 4.13 & 1.09 & 1.20 & 561 \\
\hline 19 & C-14 & 89 & 8 & 3.92 & 1.15 & 1.32 & 408 \\
\hline 20 & C-19 & 89 & 8 & 3.74 & 1.06 & 1.13 & 385 \\
\hline
\end{tabular}

Table 2 - Factor analysis

Rotated component matrix

\begin{tabular}{|c|c|c|c|c|c|}
\hline \multirow{2}{*}{ Code Name } & \multicolumn{5}{|c|}{ Component } \\
\cline { 2 - 6 } & $\mathbf{1}$ & $\mathbf{2}$ & $\mathbf{3}$ & $\mathbf{4}$ & $\mathbf{5}$ \\
\hline $\mathrm{C}-12$ & 0.814 & -0.170 & -0.841 & 0.121 & -0.166 \\
\hline
\end{tabular}




\begin{tabular}{|c|c|c|c|c|c|}
\hline C-7 & 0.911 & 0.110 & -0.119 & 0.117 & 0.028 \\
\hline C-11 & 0.891 & 0.090 & 0.007 & 0.262 & -0.063 \\
\hline C-5 & 0.863 & 0.032 & 0.0862 & 0.045 & 0.203 \\
\hline C-4 & 0.474 & -0.067 & -0.091 & 0.215 & 0.321 \\
\hline C-15 & -0.056 & 0.854 & 0.063 & -0.127 & 0.071 \\
\hline C-17 & -0.005 & 0.857 & 0.093 & 0.375 & -0.056 \\
\hline C-1 & -0.092 & 0.834 & 0.077 & 0.278 & 0.092 \\
\hline C-9 & -0.081 & 0.782 & 0.177 & -0.127 & 0.286 \\
\hline C-6 & -0.022 & 0.123 & 0.076 & 0.853 & 0.105 \\
\hline C-18 & 0.213 & 0.152 & 0.310 & -0.057 & 0.670 \\
\hline C-2 & -0.047 & 0.008 & 0.721 & -0.019 & 0.004 \\
\hline C-8 & -0.093 & 0.141 & -0.203 & 0.027 & 0.892 \\
\hline C-16 & -0.105 & 0.202 & -0.175 & 0.863 & -0.133 \\
\hline C-10 & -0.022 & 0.286 & -0.192 & 0.780 & -0.009 \\
\hline C-13 & 0.187 & 0.219 & -0.077 & 0.016 & 0.825 \\
\hline C-20 & -0.274 & -0.180 & 0.067 & 0.744 & -0.199 \\
\hline C-3 & -0.031 & 0.238 & 0.767 & 0.056 & 0.343 \\
\hline C-14 & 0.150 & -0.702 & 0.908 & 0.263 & 0.020 \\
\hline C-19 & 0.057 & -0.095 & 0.059 & 0.365 & 0.854 \\
\hline
\end{tabular}

After factor analysis, C-7,C-11,C-5,C-4, and C-12 were grouped together which represents senior management support; C-15,C-17,C-1, and C-9 were grouped together which represents co-operation and co-ordination among IT support teams; C-2, C-3 and C-14 were grouped together which represents justification of large investment; C-16, C-6, C-10, and C-20 were grouped together which represents proper documentation and effective process design; and finally, C13, C-8, C-19 and C-18 were grouped together which represents premium customer's support. 


\subsection{Recommendations to overcome challenges}

Each participant was asked the following question during the interview to get the participant's insights as for how the challenging areas were managed to overcome by ACIS Ltd.

- How did ACIS Ltd. manage to overcome the top challenges in implementing ISO $20000 ?$

The interviewees gave suggestions for overcoming challenges of different categories. Most of their answers and responses to this question were concerning the effective process design, setting organizational priority and top management support. The majority of the respondents also agreed that if the above challenges are managed to overcome, challenges in other areas such as justification of significant investment, co-operation and co-ordination among IT support teams, proper documentation and premium customer support should be addressed. Figure 5 shows the summaries of the suggestions after relevant analysis.

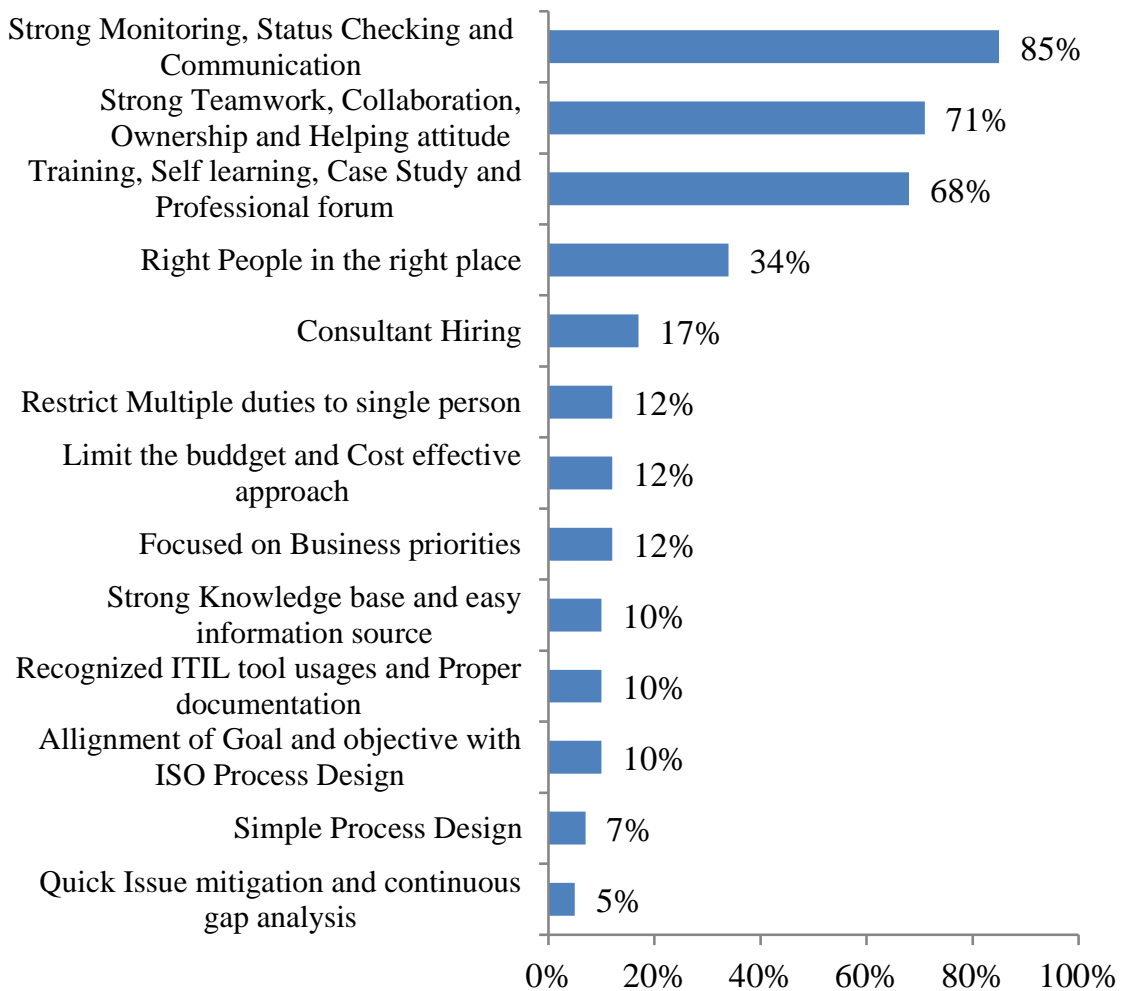


Figure 5 Summaries of the suggestions of IT Professionals of ACIS.

Recommendations of the 45 key interviewees were grouped together based on data analysis. $85 \%$ of the participants suggested that many challenges could be avoided by strong monitoring, regular status checking and communication within the IT support teams. $71 \%$ of the participants believed that strong teamwork, collaboration, ownership and cooperative attitude could address many challenging areas. $68 \%$ of the participants suggested that majority of the challenges could be overcome with the training and self-learning. $34 \%$ of the participants recommended to go through previous case studies related to ISO 20000 implementation and suggested to connect professional forum to address the challenging areas. $17 \%$ of the participants saw consultant hiring was one of the ways to overcome challenges. $12 \%$ of the participants suggested to focus on business priorities to avoid challenging areas. $12 \%$ of the participants suggested to limit the budget and take cost-effective approach to mitigating challenging areas. $12 \%$ of the participants believed in the restriction of multiple duties to avoid some challenges. Others suggestions were alignment of goals and objectives with ISO process design (10\%), recognized ITIL tool usages and proper documentation (10\%), strong knowledge base and easy information source (10\%), simple process design $(7 \%)$, and quick issue mitigation and continuous gap analysis (5\%).

\section{Proposed framework for ISO 20000 implementation}

Many challenges to the implementation of ISO 20000 were identified in this study. A number of suggestions were also suggested by the respondents to overcome the challenges. Based on those suggestions, a reference model of ISO 20000 implementation was developed. Figure 6 illustrates the reference implementation model where challenging areas are represented by the 5 of the 6 boxes. This model shows how each challenging area could influence one another and increase or decrease the chances of the overall success of the implementation. 
Communication is at the center of each of the challenging areas in this model and should be regarded as the most crucial element to formulate any strategies to implement the ISO 20000 to meet the challenges identified by this study. Communication within organization is vital to promote the understanding of the standard and its processes, increase maturity and build relationships. An organization's readiness $\mathrm{t}$ for ISO certification is critical, and it is also suggested that new organizations follow the best possible standard under its domain before going for certification. ITIL should roll out first in the organizations, and after some years if organizations are matured enough, they can go for certification.

Many organizations spend a lot of money on record keeping, but ITSM tools are the recommended tools for keeping various records. Resource planning needs to be done very carefully. People who are currently working with another standard can be involved initially, but for a long duration there should be a permanent position for each of the process area. A single person should not be given multiple responsibilities. There should be dedicated process managers for each process and strong central monitoring team headed up and supported by top management should be in place for successful implementation.

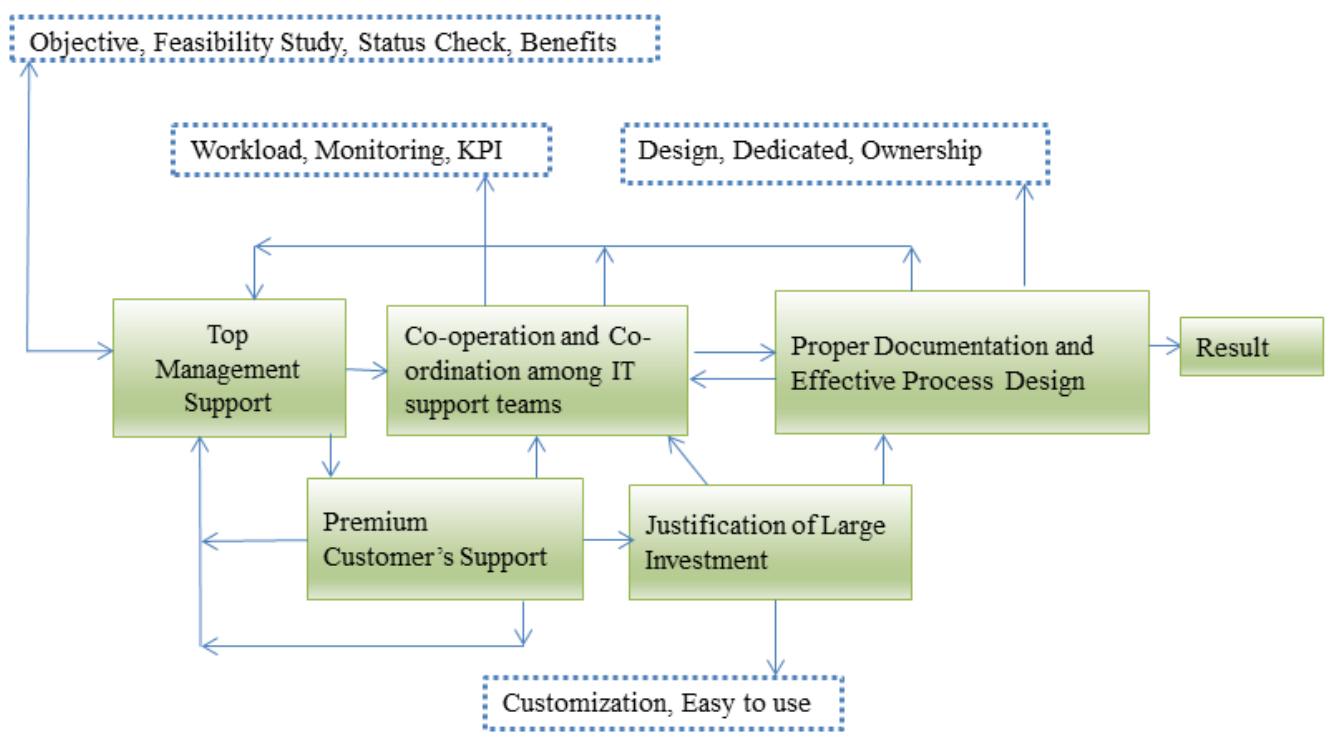


Figure 6 Reference Model for Implementation of ISO 20000

Support to premium customers should not be reduced during implementation of ISO 20000. Reducing support to customers may create a negative impression to the executive management. Besides status check, rewarding and monitoring top managers should declare the project priority for successful implementation. Organizations should not depend on external auditors rather they should formulate a well set of internal auditors for successful implementation and successful running of the standard within the organizations. Sometimes process managers design the process so poorly that it cannot be implemented or even if it is implemented, it would not bring benefit for the organizations and eventually it may create a long hole for the whole process. Process designers must be familiar with organizations' goal, and capacity or capabilities of IT support people of the organizations.

\section{Discussions on findings}

In this study, several challenges for implementation of ISO 20000 in ACSI Ltd. were identified. The following five are the main challenges that must be addressed for a successful implementation of ISO 20000.

a) Senior management support. Top management support was the major challenge during implementation of ISO 20000 in ACIS. Budgeting, restructuring, role assignment and convincing customers and selecting good process managers are the prime duty during this period. Every investment needs senior manager's direct support and if it is a significant amount of money, their support becomes most crucial part of the project. Commitment from managers and a status check is vital for project completion.

b) Justification of significant investment. Purchasing ITSM tools and development of infrastructure require huge investment initially. Return on investment should be clearly understood by all. Before going for any investment, it is one of the 
biggest challenges for the management to show people visible benefits at the initial stage

c) Premium customer support. During implementation, premium customer support was the important factor. ACIS continued the high level of assistance to premium customers besides other jobs. Maintaining the focus on client's need in ISO 20000 implementation period was a challenging task for IT support people.

d) Co-operation and co-ordination among IT support teams. Co-operation and coordination is also an important challenging area during implementation. Synchronization is required to achieve the goal. Consistency is also necessary in this case. A ITSM project is much more complex compared to any project because it is related to a process which crosses departments, and it requires more collaboration and communication.

e) Proper documentation and effective process design. Proper documentation is the key for audit purpose and ignoring this issue will bring negative impact to achieve certification. Process managers are the key person for implementation. Ineffective and inefficient process design may destroy the whole process. Ownership is the key factor in this case. All process managers have to take full ownership of his/her processes. Rolling out the processes, customizations, facing audits, preparing organizations for audits completely depend on process managers. There are many processes in a company, and good process managers are the key to design a new process by knowing all the process. One process should not overlap other processes.

The challenges found in this study (senior management support, justification of significant investment, premium customer support, co-operation and co-ordination among IT support teams, proper documentation and effective process design) contrast, to a significant extent, with other studies where challenges to other ISO standard and certification processes were investigated. For example, Sfakianaki and Kakouris [33] analyzed obstacles to ISO 9001 certification for small and mediumsized enterprises (SMEs) in the Greek food and beverage industry (FBI). They 
observed that bureaucracy, demands on time and resources, a lack of proper guidance from top management, and employee reactions were the important challenges to ISO 9001 for SMEs in the FBI. Challenges to ISO 14001 environment management systems in the private and public organizations of the United Arab Emirates were explored by Waxin et al. [34]. They reported that a lack of competent employees, practical challenges to implement ISO 14001, inadequate government regulations, high cost and a lack of management support were the most significant challenges to ISO 14001 implementation in the United Arab Emirates. In a study to identify challenges to implementing International Information Security Standard ISO 27001, Abusaad et al. [35] found that identifying the organization's assets was the most significant obstacles to ISO 27001 certification in Saudi Arabian organizations.

\section{Conclusion, implications and Limitations to the study}

This research focused on the challenges faced by the largest IT company in Bangladesh that took initiative for ISO 20000 certification and recommended some ways to overcome the challenges. ISO 20000 certified organizations are located mostly in developed countries. IT infrastructure is not up to the mark for developing countries like Bangladesh where organizations must be able to manage big data. Besides, elements of Industry 4.0 such as Big data, IoT and smart factory concepts are shaping the future of manufacturing industries. Moktadir et al. [36] found that technology-related barriers are significant barriers to big data analytics in manufacturing supply chains. In [37], it was reported that a lack of technological infrastructure is the most significant challenge to implement Industry 4.0 in the leather industries of Bangladesh. Huge investment are required for developing infrastructure that leads to the negative impression initially to implement this standard especially in developing countries. There are some legal requirements that cannot be neglected, and it can be country specific. The identified challenges can give directions to organizations to implement ISO 20000 in an effective way. ISO 
20000 can help organizations achieve competitive advantage and business excellence.

\subsection{Theoretical and managerial implications}

ISO 20000 ensures IT service management processes aligned with the needs of the business interests and international best practices $[8,10]$ for dealing with data for making critical business decisions. It helps organizations benchmark the delivery of IT services, measure service levels, and assesses their performance [38]. A knowledge gap on challenges to implementation of ISO 20000 exists in the ICT literature in the context of emerging economies. Thus, this research contributes to the theory by expanding the knowledge of ICT literature by identifying significant challenges that IT firms may face during implementing ISO 20000. This research also contributes to the existing ICT knowledge-base by providing a framework to implement ISO 20000, which academics can use for further updating the ICT literature in the future.

Identification of challenges to ISO 20000 can be beneficial to local and multinational IT-based companies interested in managing big data and starting IT related business in emerging economies like Bangladesh, India, China, Thailand and so on. Organizations planning to implement ISO 20000 should carefully consider all challenges that were identified in this study and can take measures to resolve those challenges. Some challenges can be addressed by education, awareness, and proper training. Challenges that are related to extra investment can be treated by identifying organizations' priorities and allocating the necessary budget. Communication within the IT service management organization is vital to promote the understanding of the standard, increase maturity and build relationships. Senior management support is the most challenging factor identified in this study for successful implementation of ISO 20000. Justification of significant investment, proper documentation and effective process design, co-operation among IT support teams and premium customer's support are the other challenging areas. The 
expected value of implementation can be fully achieved only when these challenges are adequately identified, and necessary actions are taken proactively.

\subsection{Limitations to the study}

There are some limitations to this study. This work is based on data collected from managers and staff having working experience in IT firms. To gain a better understanding and generalization of the challenges, a cross-organizational and cross-country study can be conducted in the future. Another promising research direction would be to formulate an interpretive structural model (ISM) of the challenges to find the interrelationships among them.

Conflict of interest: No conflict of interest was reported by the authors.

Acknowledgement: The authors acknowledge the supports of staff from ACIS Ltd. for carrying out the research work successfully. The authors would like to thank the editor and anonymous reviewers for their insightful comments and suggestions, which helped us enrich the quality of this manuscript.

\section{References}

[1] Bugyei, K. A.; Obiri-Yeboah, K.; Kavi, R. K. Assessing the Impact of ICT on Research Activities in Ghana: A Case Study of Selected Council for Scientific and Industrial Research (CSIR) Institutes. J. Inf. Knowl. Manag. 2017, 16(01), 1750007.

[2] Yu, X.; Chen, Y.; Nguyen, B.; Zhang, W. Ties with government, strategic capability, and organizational ambidexterity: evidence from China's information communication technology industry. Inf. Technol. Manag. 2014, 15(2), 81-98.

[3] Mohamed, M. S.; Mohamed, M. A.; O'Sullivan, K. J. (2010). Information and Communication Technology (ICT) Policy: A Quantitative Assessment for Sustainable Development. J. Inf. Knowl. Manag. 2010, 9(03), 227-239.

[4] Oliveira, T.; Martins, M. F. Literature review of information technology adoption models at firm level. Electron. J. Inf. Syst. Eval. 2011, 14(1), 110-121. 
[5] Kaufmann, M. Big Data Management Canvas: A Reference Model for Value Creation from Data. Big Data Cogn. Comput. 2019, 3, 19.

[6] Haseeb, M.; Hussain, H. I.; Ślusarczyk, B., \& Jermsittiparsert, K. Industry 4.0: A Solution towards Technology Challenges of Sustainable Business Performance. Soc. Sci.2019, 8(5), 154.

[7] ICT review report, Katniss Inc. Available online:

http://www.tjyh2003.com/jianqiao/G12_Katniss_website/index.html. Accessed on 29 March 2018.

[8] Cots, S.; Casadesús, M.; Marimon, F. Benefits of ISO 20000 IT service management certification. Inf. Syst. E-bus. Manag. 2016, 14(1), 1-18.

[9] Leite, C. D.S.; Rodrigues, J. G. P.; Da Silva Sousa, T.; da Hora, H. R. M. . IT services management and ISO 20000: A case study in an IT remote support company. Manag. 2014, 4(2), 38-49.

[10] Disterer, G. (2009). ISO 20000 for IT. Bus. Inf. Syst. Eng. 2009, 1(6), 463-467.

[11] Massoud, M. A.; Fayad, R.; Kamleh, R.; El-Fadel, M. (2010). Environmental management system (ISO 14001) certification in developing countries: challenges and implementation strategies. Environ. Sci. Technol. 2010, 44(6), 1884-1887.

[12] Trienekens, J.; Zuurbier, P. Quality and safety standards in the food industry, developments and challenges. Int. J. Prod. Econ. 2008, 113(1), 107-122.

[13] Gimenez, L.; Joliffe, D.; and Sharif, I. Bangladesh, a Middle Income Country by 2021: What Will it Take in Terms of Poverty Reduction? Available on: https://openknowledge.worldbank.org/handle/10986/18668 (accessed on March 21 2016).

[14] Chowdhury, M.I. Prospects of ICT in Bangladesh. Available on http://www.theindependentbd.com/arcprint/details/38046/2016-03-22 (accessed on March 21 2018).

[15] Bangladesh's ICT Industry: A Boon for Women's Employment. Available on: http://www.worldbank.org/en/news/feature/2015/05/08/bangladeshs-ict-industrya-boon-for-womens-employment (accessed on 21 March 21 2018). 
[16] Ghosh, J Big Data Analytics: A Field of Opportunities for Information Systems and Technology Researchers, J. Glob. Inf. Tech. Manag. 2016, 19(4), $217-222$.

[17] Kang, K.-D.; Chen, L.; Yi, H.; Wang, B.; Sha, M. Real-Time Information Derivation from Big Sensor Data via Edge Computing. Big Data Cogn. Comput. $2017,1,5$.

[18] Fung, H. Using Big Data Analytics in Information Technology (IT) Service Delivery. Int. Tech. and Appl. Res. 2013, 1(1), 6-10.

[19] Zhang, J., Li, J., Jiang, Y., Zhao, B. The Overview of the Information Technology Industry Chain in Big Data Era. Future Information Technology. 2014, 309, 429-432. Springer, Berlin, Heidelberg. https://doi.org/10.1007/978-3-642-55038$6 \_66$.

[20] Zaidi, S. A. H.; Mirza, F. M.; Hou, F.; Ashraf, R. U. Addressing the sustainable development through sustainable procurement: What factors resist the implementation of sustainable procurement in Pakistan? Soc.-Econ. Plan. Sci. 2018. https://doi.org/10.1016/j.seps.2018.11.008.

[21] Feng, Y. C.; Huang, Y. C.; Ma, X. M. The application of Student's t-test in internal quality control of clinical laboratory. Front. Lab. Med.. 2017, 1(3), 125-128.

[22] Cots, S., Casadesús, M. Exploring the service management standard ISO 20000. Total Qual. Manag. Bus. Excell. 2015, 1-19. .

[23] ISO Survey of certifications to management system standards. Available on http://isotc.iso.org/livelink/livelink?func=1l\&objId=18808772\&objAction=browse\&vi ewType=1 (accessed on January 15 2016).

[24] Jäntti, M. Challenges in Implementing IT Service Management Systems, ICONS Conference, University of Eastern Finland, Finland, 2012.

[25] Tan, W. G.; Cater-Steel, A.;; Toleman, M. Implementing IT Service Management: A case study focusing on critical success factor. J. Comput. Inf. Syst. 2009, 50(2), 1-12.

[26] Hochstein, A.; Tamm, G.; Brenner, W. Service-oriented IT management: Benefit, cost and success factors, Proceedings of the Thirteenth European Conference on 
Information Systems, IBM IT Facilities Consolidation and Relocation Services - data Centre consolidation, Regensburg, Germany, 2005.

[27] Szabó, Z- Fehér, P. Current Challenges of IT Service Management in Hungary. Conference Proceedings of CONFENIS, Corvinus University of Budapest, Hungary. 2009.

[28] Iden, J.; Eikebrokk, T. R. Implementing IT Service Management: A systematic literature review. Int. J. Inf. Manag. 2013, 33, 512-523.

[29] lshenqeeti, H. Interviewing as a Data Collection Method: A Critical Review. English Linguist. Res. 2014, 3(1), 38-45.

[30] Belvedere, V.; Grando, A.; Legenvre, H. Testing the EFQM model as a framework to measure a company's procurement performance, Total Qual. Manag. Bus. Excell. 2018, 29(5-6), 633-651.

[31] Maalouf, M. \& Gammelgaard, B. Managing paradoxical tensions during the implementation of lean capabilities for improvement. Int. J. Oper. Prod. Manag. 2016, 36(6), 687-709.

[32] Camilleri, M. A. Measuring the corporate managers' attitudes towards ISO's social responsibility standard. Total Qual. Manag. Bus. Excell. 2017, 1-13.

[33] Sfakianaki, E.; Kakouris, A. Obstacles to ISO 9001 certification in SMEs. Total Qual. Manag. Bus. Excell. 2018. https://doi.org/10.1080/14783363.2018.1490640.

[34] Waxin, M. F.; Knuteson, S. L.; Bartholomew, A. Drivers and challenges for implementing ISO 14001 environmental management systems in an emerging Gulf Arab country. Env. manag. 1-12. http://link.springer.com/article/10.1007/s00267-017-0958-5.

[35] AbuSaad, B.; Saeed, F. A.; Alghathbar, K.; Khan, B. Implementation of ISO 27001 in Saudi Arabia-obstacles, motivations, outcomes, and lessons learned. The Proceedings of the $9^{\text {th }}$ Australian Information Security Management Conference, Perth, Australia, 2011. 
[36] Moktadir, M. A.; Ali, S. M.; Paul, S. K.; Shukla, N. Barriers to big data analytics in manufacturing supply chains: A case study from Bangladesh. Comput. Ind. Eng. 2019, 128, 1063-1075.

[37] Moktadir, M. A.; Ali, S. M.; Kusi-Sarpong, S.; Shaikh, M. A. A. Assessing challenges for implementing Industry 4.0: Implications for process safety and environmental protection. Process Saf. Environ. Prot. 2018, 117, 730-741.

[38] Aleksandrova, D. Why your organisation needs to be ISO20000 certified. Available on: https://www.itgovernance.co.uk/blog/tag/iso20000/ (accessed on 15 February 2015). 